\title{
Interview with Professor Nico Carpentier, Uppsala University
}

\author{
AURORA PATERA, Canterbury Christ Church University
}

After his keynote speech 'Culture as an integral part of the discursive-material knot' presented on $5^{\text {th }}$ July 2018 at the MeCCSA Postgraduate Network conference, Aurora Patera interviewed Prof. Nico Carpentier to explore deeper into the ideas and arguments he presented on this topic.

[AP] You talk about your theoretical contribution, the Discursive-Material Knot, as a triptych and you have produced several audio-visual works and a more recent photo exhibition in Brasilia, "Iconoclastic Controversies". How do you think the combination of theoretical research and the production of visual work can be useful for a researcher, and how did it influence your academic work?

[NC] There are multiple answers to this one question. I think, first of all, my more artisticcreative experiments are deeply grounded in theoretical reflections. They are, of course, rooted in the theoretical work in nationalism, or agonism, or participation, but, maybe more importantly, they are grounded in reflections on how to communicate academic research. And that is also a theoretical debate: Thinking through what knowledge is, how we can actually produce knowledge, how the lived, embodied experiences of researchers are also part of the generation of knowledge. Some of the audio-visual work and the exhibition work that I have done is framed by what is called arts-based research - ABR - which is driven by these theoretical questions about the role of creativity and its interconnection with knowledge production. To put it all in simple terms: One of the most fascinating aspects in these projects is that through the creation of theoretically and empirical research-driven installations, for instance, you can actually produce new knowledge. It is not a mere communicational dimension that matters there, it also has an epistemological dimension, at the same time. And of course, for me, the science communication part is important, but one of the things I found most satisfying and promising in ABR is its epistemological dimension, the knowledge production component. So, that is one part, which is very much an academic-artistic-activist practice - what I call the "triple A" hybrid identity — that is part of ongoing debates on knowledge production, but that is only one part of the answer, I am afraid.

What I am also trying to do is very connected to the discursive-material knot model: trying to translate and condense abstract theory into artistic material practice. One of the big challenges, 
for instance, of the installation I created for the "Participation Matters" exhibition at the "Respublika!" festival, which was called "The Mirror Palace of Democracy", one of these core complexities, challenges and objectives — all in one (smiles) — was the idea that a theoretical reflection on democracy could be transformed into an art installation that would not only allow the visitor to experience the complexities and the contingencies of democracy but would also allow me to communicate my theoretical position. So, there is a moment of translation present, that is, I think, extremely important: It is a translation from theory to installation. It is still a theory-driven enterprise, with all its complexities, because it requires a moment of translation that is not a copy. It is not simply putting a book on a display table, saying: "Look, here is the materialisation of my theoretical reflections". It is not an artistic practice that is totally isolated from the theoretical reflections: It is very much an assemblage in itself. This is about combining the discursive and the material, but in a different way than the ways that we are used to doing this. It is not the book or the article (which are, of course, also forms of material output), but it is the installation that allows you to see, experience, physically enter the contingencies of democracy, and in some cases bang your nose against one of the glass walls of the mirror palace, as actually one of the coordinators of the art centre did. It wasn't very funny or pleasant, but symbolically it was actually quite interesting. This is also what embodiment means, it is these little and detailed, but ever so important, practices of visitors, curators, directors of art institutes, ... that then become part of the production of knowledge. Even an at first sight very banal event — somebody hurting herself because she didn't see the glass wall was there - raises theoretical issues: What does the limit of democracy mean? When do you leave and how painful is it to actually leave democracy? Which is a very contemporary discussion. It might sound banal, but in the present conjuncture, it is (again) an extremely important question, referring to deeply problematic political configurations - look, for instance, at Brazil and some other countries in the world that are sliding down a slippery slope and literally bumping into the walls of non-democracy.

\section{[AP] In your work you mention the importance of high theory. What do you think of the relationship between high theory and empirical work? Is there a gap to bridge? What is the position of your theoretical contribution in regards to this?}

[NC] The relationship between high theory and empirical work could be mediated in a wide variety of ways and I'd hate to be the one that defends one particular model as the ultimate solution to all problems. It is a very complicated relationship and there is not one answer, there are many different paradigmatically driven answers to this question. What I do think is that we should not discredit either of them. Still, my preferred choice, and the model that I would like to defend, is the radicalisation of both. I do think we need radical theory, in the meaning of 
high theory - reaching high levels of abstraction — but also radical as in radically critical. We also need radical research, and again, in both meanings. We need the radical confrontation of our thoughts and perspectives, misunderstandings and assumptions, with social practice and its complexities and its contingencies. But we also need critical research; radical research in that second meaning. We need to find ways of reconciling both, without creating hierarchies, without arguing that theory is necessarily superior to empirical research or that empirical research is superior to theory, which is something that doesn't always happen in academic practice. We need a very balanced approach that respects both of them and that allows both of them to exist in their radical versions. That is the key starting point for me, but at the same time, I think it is very important to emphasise that this is only one perspective, and this is not a discussion where there has to be only one dominant perspective.

Diversity, in the different ways of handling these relationships between high theory and empirical research, is crucial to acknowledge, but this does not undo that the radicalisation of theory and empirical research is an equally important starting point for me. I think you can see how I work in, for instance, The Discursive-Material Knot, with the use of the different platforms. The idea behind using different platforms is to create different entry points into one publication, not privileging a linear reading that goes from A to Z. And if you look at the platforms of that book - there are three of them - they have different levels of abstraction: The first, in particular, is a very abstract discussion of that relationship between the discursive and the material, but if you look at the third platform, then you'll find a very concrete research practice, which is a case study of a Cypriot community media organisation, CCMC, and its radio station, which is called MYCYradio. That third platform is very much empirical research based. Having a platform structure deployed means that you can start anywhere, you can enter the book at the more abstract level, or you can enter the book at the more concrete level. Both choices are perfectly fine: The platforms are written in such a way that you can get the more significant meanings and interpretations (at least how I see them) at each of these entry points. Of course, ideally, a reader takes note of all three platforms, but it is perfectly fine for me that the reader sticks to one platform or chooses a different order of platforms to read. And I think that is, in a way, a materialisation of the way I think about the relationship between high theory and empirical research, where there is no privileging of one over the other.

\section{[AP] Is this what you mean when you write about a horizontal approach?}

[NC] It tries to be, in the way of entering the book using the different platforms. Of course, it is not my idea, this is the Mille Plateaux by Deleuze and Guattari and their way of thinking. While the joke that I endlessly repeat is that I tried to be a bit more modest, not having a 
thousand platforms but three platforms only, horizontality also plays a second role in thinking through the relationship between the discursive and the material itself, because they are the two starting points that I use, Laclau and Mouffe's discourse theory, but also new materialism. Even if I think that I try to deal with both traditions in the most respectful way - and they deserve exactly that - I also sense, when reading the subtext of these approaches, that there is still an attitude of privileging of their own approach and a paying lip service to what is important for the other approach. So, discourse theory acknowledges the importance of the material, but it does not develop it sufficiently, and new materialism acknowledges the importance of the discursive, but would not really develop it that much either. Horizontality, for me, is also the creation of a non-hierarchical approach between these two, that actually tries not to replicate these hierarchies, not to create this distinction, but to look at the assemblage and the entanglement and see how it plays out in social practice and how it is played out in theory, again, without creating the kind of hierarchy that suggests that, at the end - or in the last instance, to use a famous formulation - one is more important than the other.

\section{[AP] Your Discursive-Material Knot ties together and re-reads many theoretical concepts, and tries to bring together two different dimensions: the material and the discursive. How could your work, as a theoretical framework, be used to change our interpretation of reality by the researchers who choose to employ it?}

[NC] One way in which the combination of these two components, the material and the discursive, really matters, is that it makes researchers sensitive to the one component which is not very significantly present in their field. Take, for instance, the study of nationalism: If you start looking at, say, the non-primordialist approaches towards nationalism, they put a lot of emphasis on the discursive, and there I would argue that the material actually needs more attention. It is almost like a deconstruction, where you also choose the other side, where you identify the binary oppositions and where you try to see how to overcome the dualistic approach. I would argue that having this other-side-that-is-often-quite-absent in mind, is significant in enriching analyses of a wide variety of social domains. One example is the ongoing discussion about algorithms, where we tend to look at a very material component: How particular algorithms produce particular content, which basically refers to which text we are offered on our screens. But behind all this, there is also a hugely important discursive reality, where particular subject positions, for instance the subject positions of the creator, the programmer, the user, the player or the gamer (depending on the particular reality we are looking at) has an enormous impact on how algorithmic culture is developing. It is this sensitivity that matters to me. Don't forget that my work on the discursive-material knot is still driven by post-structuralist approaches, which means that you have to keep in mind that context 
matters, that whatever research question we deal with, whatever social reality we are investigating, we should also acknowledge its specificity and we should not use one-answerto-all solutions. Of course, different themes, different fields, will have their own answers, but this sensitivity, I think, is quite important. Another example is conflict studies, which I found surprisingly focussed on the material. But then there is this discursive construction of the enemy, which plays a vital role in conflicts, and which is, in a lot of academic publications still too absent. Of course, some scholars, including communication and media studies scholars, have argued that conflicts studies, as a whole, has not really come to terms with this discursive component, and these colleagues are trying to remedy this problem. From my perspective, a discursive-material knot, a theory of entanglement, might make us much more sensitive to this too absent component in our research, and allow us to deal better with this problem.

\section{[AP] You mention that your framework can be used for the study of communication and media, but also has an interdisciplinary vocation. To which other disciplines do you think it can be applied?}

[NC] First of all, I am structurally but also emotionally grounded in media and communication studies. That is my tribe (smiles). This is one of the locations of knowledge production where I situate myself. This is my imagined community and that really matters more than we often like to admit or even communicate. Quite a lot of my research looks at media content in its organisational contexts, at discourses about media organisations or key media actors, or at communicational processes and processes of mediation, and that really, definitively matters to me. At the same time, I am also equally interested in conflict studies, which has always been part of my work. But also discourse studies, of course, is an area where I would find interest in. Hopefully, some of the studies that I have been doing provoke some sort of an interest in these academic fields too. Another field of academic inquiry that I should not forget to mention is political studies, and more in particular the field of democratic theory. My work is fascinated by the redistribution of power. Yes, I tend to look at communicational practices and environments of mediation, but at the same time, I think my fascination for power moves way beyond these fields. I think that the family as a location of power is intensively fascinating, I think that the workplace, university, school, ... are just as fascinating as media organisations are, from this perspective. Especially the study of participation, linked to how I have been working with participation (as the redistribution of power) and linked to the discursive-material knot, opens the doors into so many different areas, that the research options become virtually endless. I am actually deeply grateful for that because it implies that the world, from a researcher's perspective, remains an incredibly fascinating place, as every social practice has these dimensions of power. And every social practice has these potential dimensions of the 
redistribution, equalisation and democratisation of these relations. And that is a very luxurious position to have, to be fascinated by processes that are present in virtually every academic field.

\section{[AP] Your study highlights the connection between participation and peacebuilding. Do you think the study of assemblages like the one you propose in your study can be used for social transformations? How?}

[NC] Yes, one of the important outcomes of the CCMC case study is that there is an almost natural connection between participation and peacebuilding. They strengthen each other. In that particular case study, it becomes very, very visible. At the same time, it incorporates a warning: This connection between participation and peacebuilding is not an automatic connection. No connection, no articulation, is automatic. We can't assume that participation will lead to agonism and the other way around. At this point in time, I am working with a colleague - Hillel Nossek — on an article that analyses a number of Israeli community television groups. These groups are not broadcasters, because the Israeli media field is differently organised, they are production groups. In many cases, there, the automatic link that is very present in the Cypriot case study is not present at all, for a number of reasons, one of them being a much more closed definition of the community. These are organisations that serve the community by allowing the community to represent itself and to take charge, control, over their communicational practices. That is the basic idea, but if you define the community in a very strict way and do not articulate that community with other communities, the peacebuilding logics do not work that well. So there are interesting cases where this connection is not as automatic as it was (and is) in the Cypriot case. There's hope on the one hand, that the participatory logic can strengthen peacebuilding, but there are also some counter-cases that I very consciously identified, where this connection is not as automatic, so we should be careful not to assume automatic links.

At the same time, participation in its articulation with peacebuilding offers opportunities for social change. I think that, for a wide variety of reasons, the logic of participation and peacebuilding map onto each other. That allows for the creation of more just, fair, and peaceful societies. There is a potential there, but at the same time there is also a grim warning. As a concept, social change is often used to refer to more just, balanced, societies, where individuals are empowered and, to put it in simple terms, happier. But social change can also go into different directions. We hardly ever use the term "social change" in that more negative sense, but social change can also refer to the creation of harsher societies, where people tend, for instance, to destroy each other. Currently, that negative type of social change seems to be on the winning hand, at the global level. There are serious reasons for concern, that we are moving into a direction that actually decreases empowerment, fairness, and peace. That we are moving 
towards a much harsher, crueller world. And that is also a process of social change, that some even seem to support and prefer. I would not consider myself to be one amongst them, but there is a clear push into a direction of social change that I would define as undesirable.

And here we shouldn't forget that participation, at least in its more formal version, can be used to support these less beneficial, less just, more violent forms. And there, there is a very strong need to further develop what I would call participatory ethics: To develop ethical sensibilities that prevent the abuse of participation for non-democratic means. Trolling is one example, troll farms, flaming, all these different social practices that are destructive and that we've seen become very visible over the past years. They are connected to procedures that are only participatory in form. The problem is that these procedures empower small groups, and that they bring out very antagonistic voices, which then silence the voices of others. In some cases, these procedures are actually conducive to the destruction of the voices of others. We need to think much more about participatory ethics that protect us from having the formal procedures of participation being used against participation and democracy itself. I think that is one of the big challenges. To sum up what I was trying to say: On the one hand yes, there is hope that participation, peacebuilding, social justice, empowerment can become aligned and part of one benevolent assemblage, but we can also go into different directions, into much darker times.

\section{[AP] What is in your opinion the role of discourse theory, as revisited in your theoretical work, in a society that seems to be more and more confrontational and conflict-oriented even in the absence of actual conflicts?}

[NC] One of the most important contributions of discourse theory is that it emphasizes the importance of conflict in social relations. With this emphasis, discourse theory disconnected conflict from being articulated as necessarily negative and violent. What discourse theory has done, is to look at politics as inherently conflictious, but at the same time, it raised the issue of how we deal with conflict in ways that are democratically acceptable. I think that this is where I deeply connect with discourse theory, because the way that I see the world, my ontology, is very much aligned with it. I see nothing but these confrontations, I see nothing but differences. I think that even if we look at fairly homogeneous communities, we should not become blind to what divides these apparently homogeneous communities, to the many, many different layers of contradictions that we sometimes want to very gently skim over and ignore. I must confess that I am fascinated by these differences that also produce conflict, by these different interests, different identities, different positionalities, different subjectivities. Yet, we still manage to create some kind of coherence and unity in that incredibly conflictious world. The point that discourse theory raises, is that we can do that in different ways. We can reconcile these differences in more peaceful and agonistic ways, where we acknowledge the other as an 
adversary with whom we disagree, but where we definitely acknowledge the right of that other voice to exist. On the other hand, of course, there are more violent ways of dealing with the other: In some cases this concerns symbolic violence, linguistic violence, ... but in other cases this is very material violence, for instance, the killing of the other voice. What discourse theory has done, I think, is put conflict on the agenda as a key ontological principle, and at the same time it raised the question: What kind of conflicts are democratic and what kind of conflicts are waged in non-democratic ways.

Discourse theory, in that sense, is very normative, it privileges agonism over antagonism, it defends that agonistic dimension of dealing with the other. It is a very strong voice in accepting conflict as an ontological condition, but at the same time in not accepting that violence is the only way out, accepting that we can engage in the political struggle with each other on an endless basis and still stay within the realm of democracy. It is a very normative but also a very hopeful approach, that is typical, I think, for discourse theory. Obviously, the idea that we can peacefully disagree does not exclusively belong to discourse theory. There is, for instance, a very long tradition in philosophy dealing with the concept of freedom of speech that acknowledges the adversary, so I do not want to claim that discourse theory has ownership of this idea. Still, discourse theory has strongly thematised it, not only looking at individual voices but also at the confrontation of different discursive orders, moving away from an exclusive focus on the individual, from the one person that engages in disagreement with another person, and entering into an analysis that looks at discourses, at ideas, in the way that they confront with each other and engage in political struggle.

\section{[AP] You analysed the case CCMC/MYCYradio in Cyprus, using your theoretical framework, which other contemporary conflicts do you think could (or should) be analysed through this framework?}

[NC] There are a couple of areas that I think should be looked at, and I think that the Israeli case study brought me to an incredibly significant part of the world, with a conflict that matters in its own right, but that also drives a substantial part of the global conflicts. I do think that is one of the areas to look into and it is also part of my research agenda. At the same time, partially because of the "Iconoclastic Controversies" photo exhibitions, nationalism moved up on my research agenda. It is a fascinating problem and I, of course, have been very much exposed to it, as I grew up in Belgium. I do think we need to start thinking about nationalist voices in combination with populist voices in Europe (and beyond) much more than before. I am obviously not the first to say this. But looking at nationalism from a discursive-material knot perspective is very necessary, which includes looking at how nationalism is very much related to the body, related to space, related to blood - there is the famous German expression "Blut 
und Boden", blood and soil, ... All this is deeply material. I think these logics of alterity, that are driven by populism, nationalism and racism are one of the areas that we urgently need to look into. This is important from a democratic perspective as well, not only because of a general, more abstract, research interest. In the European context, we do not have that much time left. What we are now doing in Europe is preparing for another violent confrontation. We are sowing the seeds of war. It might take ten or twenty years, but this implies that there is an urgent need to look at other ways of dealing with the Other, there is a need for the permanent critique of more antagonistic practices, and there is a need to emphasize those social practices that use a more agonistic approach towards the other. This, of course, implies interventionist research, getting your feet wet, it implies defending some of the core principles that are dear to us. This maybe pushes us sometimes to the edges of what might be comfortable to do, but I think it is high time. From my perspective, as a researcher, I think this is a very important domain to explore.

\section{[AP] To what extent the current affairs have influenced your theoretical research?}

[NC] I had a wonderful discussion, some time ago, with Henry Jenkins in the journal Convergence. One of the conclusions that we came up with was that for Henry Jenkins the glass is often half full. I was then supposed to say "for me, it is half empty". Instead I added that probably both of us wanted to have different, better glasses. This is half a joke, but I think that that desire for a better world, also looking at practices that have that promise of benevolent social change, is something that binds us together. Maybe we have different levels of optimism, but this fascination for people that create a better world today is very important to the both of us. And maybe I am the one that tends to add some of Hakim Bey's reflections to this equation, reminding us that maximalist participatory democratic practices are often temporary autonomous zones, showing how vulnerable these practices actually are, how quickly they disappear, and how vulnerable they are to external forces that can destroy them. In that sense, the context of violent conflict, the endless wars, is equally important to me. Unfortunately, it is hard to find a phase in my career (and life) where I have not been dealing with these dark sides, simply because there have been so many. We have not managed to reach peace, to put it mildly. This endless succession of extremely violent practices has played a very important role in my own work, as they have led me to trying to think through ways that would help to avoid of this kind of bloodshed. And also, of course, being aware of the global dimensions, not only focussing on Europe, but also taking our colonial past into consideration - remember, I am Belgian - but also taking global responsibilities into consideration, and seeing how Western 
countries continue to wreak havoc throughout the world. That sense of responsibility, combined with a sense of hope, is structurally important for me.

\section{[AP] Which do you think are the biggest theoretical challenges for communication and media researchers today?}

[NC] It is up to the individual researcher and research schools to come up with different ways of dealing with this complexity (smiles). My own position is based and grounded in the acknowledgement that we are part of society, that we are not outside society, that we are not standing at the sidelines of the playing field, observing, but that we are deeply entrenched in society. Especially if you do research on participation, it is very hard to position yourself outside of these ideological struggles. Every definition of participation that you use, brings in a particular, ideological position, that you might consciously or unconsciously defend. So we are part of this ideological struggle if we do participation studies, simply because the definitions that we accept and defend are intimately connected with this political struggle over the redistribution of power. And that is only one instance. I would argue that, in general, we are not outside this playing field and that we are intrinsically connected to it. I think that one very important way of dealing with that position, is to acknowledge it. A lot has to be said on ideological self-positioning. Of course, again, this is not new: Our colleagues in anthropology have been dealing with these issues for a very long time and I do think that there's much more to learn from them, on how to deal with the need for academic honesty through explicit selfpositioning.

The second area that matters to me is that of intervention. Driven by critical analyses, we can also organise particular kinds of interventions that are more than just settings that generate new research. I think that, on the basis of our knowledge, going back to what I was talking about at the very beginning of our conversation, we can produce not only new ways of thinking, but we can also produce new experiences that actually have an additional social impact. I do not want to imply a segregation between experience and knowledge here, knowledge also creates impact — ideas are powerful - but we can also create experiences on the basis of the knowledge that we have. We can translate knowledge into social practices that can also contribute to having impact. An interventionist agenda is quite important to me. That has been translated in a lot of the artistic work that I have been doing, creating experiences - embodied knowledge, so to speak - much more than exclusively textual representations of that knowledge. I do think that interventionist research opens up theoretical problems, such as the complexities of hybrid identities, where we are in some cases a critical scholar, but in other cases actually moving into being something that is about being more than a scholar, namely about being an artist or an 

activist. There, we see different kinds of subjectivities that combine different subject positions. This is what I mean with the AAA model, the hybrid articulation of the academic, the artist, and the activist. We can come up with combinations of subject positions that push us beyond the borders of being mere academics, but in other cases, we can actually bring diverse practices in one particular identity, where we simply expand being an academic, or expand being an artist, or expand being an activist. And these are issues where we, in Communication and Media studies, need to think more about, and experiment more with. 